\title{
UPLC-MS/MS Quantification of Fenspiride in Human Plasma
}

\author{
Yuriy V Pidpruzhnykov ${ }^{1,2 *}$, Valerii E Sabko', Volodymyr V lurchenko ${ }^{1}$ and Igor A Zupanets ${ }^{2}$
}

${ }^{1}$ Bioanalytical laboratory "Clinfarm”, 3 Shevchenko Street, Irpin, Kiev Oblast, 08200, Ukraine

${ }^{2}$ National University of Pharmacy, 27 Pushkinskaya Street, Kharkiv, 61057, Ukraine

\begin{abstract}
A new simple and rapid ultra-performance liquid chromatography - tandem mass spectrometry (UPLC-MS/ MS) method has been developed and validated for the quantification of fenspiride in human plasma. Following a simple protein precipitation with acetonitrile, the analyte and internal standard (bupivacaine) were separated on an ACQUITY UPLC ${ }^{\circledR}$ BEH C18 column $(50 \mathrm{~mm} \times 2.1 \mathrm{~mm}, 1.7 \mu \mathrm{m})$ using a gradient mixture of acetonitrile and water (both containing $0.2 \%$ formic acid) as a mobile phase at flow rate $0.4 \mathrm{~mL} / \mathrm{min}$. The retention time of fenspiride and bupivacaine was 0.64 and $0.87 \mathrm{~min}$, respectively. Detection was operated in positive mode by monitoring the transitions of $\mathrm{m} / \mathrm{z} 261 \rightarrow 105$ for fenspiride and $\mathrm{m} / \mathrm{z} 289 \rightarrow 140$ for bupivacaine. The lower limit of quantification was $2 \mathrm{ng} / \mathrm{mL}$ by using $200 \mu \mathrm{L}$ aliquots of plasma. The range of quantification of fenspiride was $2-500 \mathrm{ng} / \mathrm{mL}$. Within-run and between-run precision of analysis was $<9.5 \%$, accuracy ranged from $91.5 \%$ to $112.4 \%$, average recovery from $99.3 \%$ to $101.9 \%$. The analyte was stable in human plasma following three freeze/thaw cycles and for 5 months following storage at $-70^{\circ} \mathrm{C}$. The method was successfully applied to the bioequivalence study of generic and brand coated tablets of fenspiride.
\end{abstract}

Keywords: Fenspiride; Human plasma; Respiratory tracts

\section{Introduction}

Fenspiride \{8-(2-phenylethyl)-1-oxa-3,8-diazaspiro[4.5]decan-2one. $\mathrm{HCl}\}$ is an effective drug in case of acute and chronic inflammatory diseases of otolaryngological system and respiratory tracts. It is also used as a complex therapy for bronchial asthma, allergic rhinitis and other symptoms of allergy within otolaryngological system and respiratory tracts, respiratory manifestations of measles, flu and symptomatic therapy of whooping cough

The aim of this work covered development and validation of the method for quantification of fenspiride in human plasma during bioequivalence study of coated tablets Inspiron ${ }^{\circledR}$ produced by JSC "Kievmedpreparat", Ukraine and the brand one Eurespal ${ }^{\mathbb{B}}$ produced by "Les Laboratories Servier".

The first method for the quantification of fenspiride in plasma and urine which was described in 1989 [1] included liquid-liquid extraction of analyte from the biomatrix with a mixture of organic solvents, reextraction with aqueous acid and back-extraction with an organic solvent. The extract was evaporated to dryness and reconstituted in the mobile phase. The quantification of fenspiride was run by HPLC method on the reversed-phase column, while electrochemical detection was used for concentration range from 2 to $100 \mathrm{ng} / \mathrm{mL}$ and ultraviolet detection was used for concentration range from 100 to $1000 \mathrm{ng} / \mathrm{mL}$. With the help of this quite complex method the phase I pharmacokinetic study of fenspiride in 12 healthy volunteers was conducted in 1993 [2]. In the paper [3] fenspiride and its metabolites in equine plasma and urine were detected with the help of capillary gas chromatography-mass spectrometry method. The method is also characterized by complex sample preparation which covers solid-phase extraction, analytes elution from the sorbent by strong base in ethyl acetate, evaporation to dryness under $\mathrm{N}_{2}$ and obtaining of trimethylsilyl derivates of fenspiride.

The selective LC-MS/MS method was developed for more than 250 basic drugs screening including fenspiride in the supernatant of enzyme hydrolysed equine urine after extraction on the short Oasis HLB $^{\circledR}$ column [4]. One more method based on gas chromatographymass spectrometry was developed for narcotics and stimulants in equine urine screening [5]. Fenspiride and other analytes were extracted from biomatrix by organic solvents, extracts were evaporated to dryness under $\mathrm{N}_{2}$, after that the derivates of $\mathrm{N}$-methyl-Ntrimethylsilyltrifluoroacetamide were obtained.

In the article [6] fenspiride was determined in human plasma using the liquid-liquid extraction of fenspiride and the internal standard in 1-octanol, followed by direct injection of large volume aliquot $(75 \mu \mathrm{L})$ of 1-octanol containing the analytes in the reversed-phase chromatography column and MS/MS detection.

This article describes development and validation of a new rapid UPLC-MS/MS method for the quantification of fenspiride in human plasma. The lower limit of quantification (LLOQ), was $2 \mathrm{ng} / \mathrm{mL}$ by using $200 \mu \mathrm{L}$ aliquot of human plasma and simple precipitation procedure. The developed method satisfied all regulatory requirements $[7,8]$ and was successfully applied to the bioequivalence study of coated tablets of fenspiride.

\section{Materials and Methods}

\section{Reagents, solvents and materials}

Fenspiride (Fn) reference standard (99.5\% purity) produced by Erregierre S.p.A., batch $\# 0108001$, Inspiron ${ }^{\circledR}$ coated tablets $80 \mathrm{mg}$, batch \#41209 produced by JSC "Kievmedpreparat", Ukraine and Eurespal ${ }^{\mathbb{R}}$ coated tablets $80 \mathrm{mg}$, batch \#833149 produced by "Les Laboratories Servier”, were provided by JSC “Kievmedpreparat”, Ukraine.

The internal standard (IS) bupivacaine hydrochloride (Bv) $(99.9 \%$

*Corresponding author: Yuriy $\mathrm{V}$ Pidpruzhnykov, Bioanalytical laboratory "Clinfarm", 3 Shevchenko Street, Irpin, Kiev Oblast, 08200, Ukraine, Tel: +380-442575-201; Fax: +380-443-907-372; E-mail: Yuri.Pidpruzhnykov@gmail.com

Received April 24 2013; Accepted June 20, 2013; Published June 25, 2013

Citation: Pidpruzhnykov YV, Sabko VE, lurchenko VV, Zupanets IA (2013) UPLCMS/MS Quantification of Fenspiride in Human Plasma. J Bioequiv Availab 5: 185190. doi:10.4172/jbb.1000156

Copyright: (C) 2013 Pidpruzhnykov YV, et al. This is an open-access article distributed under the terms of the Creative Commons Attribution License, which permits unrestricted use, distribution, and reproduction in any medium, provided the original author and source are credited. 
purity) was obtained from Sigma-Aldrich. Chemical structures of Fn and $\mathrm{Bv}$ are shown in Figure 1.

Methanol and acetonitrile (99.9\%, for HPLC) were obtained from Sigma-Aldrich, formic acid (98-100\%) was obtained from Riedel-deHaen.

Water was purified by "Elix-35” (Millipore, USA), final purification - by "Milli-Q Gradient" (Millipore, USA). All other chemicals were of analytical grade. Drug-free human plasma from healthy volunteers was kindly provided by JSC "Biopharma", Ukraine, each batch was accompanied by the quality certificate and stored at $-30^{\circ} \mathrm{C}$ prior to use.

Chromatography was performed in gradient mode. Solvent A: acetonitrile/water/formic acid (10:90:0.2, v/v/v), solvent B: acetonitrile/ formic acid (100:0.2, v/v).

\section{Equipment and methods}

The LC-MS/MS analyses were performed using the Waters Acquity UPLC $^{\circledR}$ system with the Waters ACQUITY UPLC ${ }^{\circledR}$ BEH C18 columns $(50 \mathrm{~mm} \times 2.1 \mathrm{~mm}, 1.7 \mu \mathrm{m})$ (both Milford, MA, USA) in combination with the Quattro Micro API triple quadrupole mass spectrometer (Micromass, Manchester, UK) equipped with an electrospray interface. MassLynx 4.1 software was used for instruments control and data processing.

Chromatography was performed at $30^{\circ} \mathrm{C}$ at a flow rate of $0.4 \mathrm{~mL} /$ min with a run time of $1.2 \mathrm{~min}$. The starting mobile phase consisted of $94 \%$ solvent A and 6\% solvent B and the linear gradient run over 0.7 min to $40 \%$ A, $60 \%$ B. Then composition was set immediately at $100 \%$ $\mathrm{B}$ and held constant for $0.1 \mathrm{~min}$, followed back to the start conditions. The autosampler was kept at $10^{\circ} \mathrm{C}$.

Detection of the ions was performed in the Multiple Reaction Monitoring Mode (MRM). The detection parameters are listed in the Table 1. Collision gas pressure (argon) was set at $2.7 \mu$ bar. The MRM parameters were determined by means of the autotune option.

\section{Standard solutions and quality control (QC) samples}

The stock solutions of Fn and Bv (400 and $200 \mu \mathrm{g} / \mathrm{mL}$, respectively) were prepared in methanol. Appropriate dilutions with acetonitrile/ water/formic acid (20:80:0.2, v/v/v) were made to produce Fn working<smiles>O=C1NCC2(CCN(CCc3ccccc3)CC2)O1</smiles><smiles>CCCCN1CCCCC1C(=O)Nc1c(C)cccc1C</smiles>

Figure 1: Chemical structures of fenspiride and bupivacaine.

\begin{tabular}{|c|c|c|}
\hline \multicolumn{2}{|c|}{ Ion source } \\
\hline Ion Mode & \multicolumn{2}{|c|}{ Electrospray+ } \\
\hline Capillary voltage & \multicolumn{2}{|c|}{$200 \mathrm{~V}$} \\
\hline Desolvation temperature & \multicolumn{2}{|c|}{$500^{\circ} \mathrm{C}$} \\
\hline Source temperature & \multicolumn{2}{|c|}{$130^{\circ} \mathrm{C}$} \\
\hline Desolvation gas (nitrogen) flow & \multicolumn{2}{|c|}{$800 \mathrm{l} / \mathrm{h}$} \\
\hline MRM parameters & Fn & 289.17 \\
\hline Precursor ion (m/z) & 104.93 & 140.12 \\
\hline Product ion (m/z) & 24 & 25 \\
\hline Collision energy (eV) & 30 & 18 \\
\hline Cone voltage $(\mathrm{V})$ & & 25 \\
\hline
\end{tabular}

Table 1: lon source and MRM parameters.

solutions of $20 ; 60 ; 200 ; 500 ; 1000 ; 2000 ; 3000 ; 5000 \mathrm{ng} / \mathrm{mL}$. These solutions were used to prepare the calibration standards. Fn working solutions of $60 ; 1000 ; 3000 \mathrm{ng} / \mathrm{mL}$ were used too for preparation of low, medium and high QC samples, respectively.

The stock solution of $\mathrm{Bv}$ was diluted with acetonitrile/formic acid $(99: 1, \mathrm{v} / \mathrm{v})$ to produce working solutions of IS $(50 \mathrm{ng} / \mathrm{mL})$.

The stock solutions were stored at $-35^{\circ} \mathrm{C}$, the working solutions approximately at $5^{\circ} \mathrm{C}$ for a month. The calibration standards and QC samples were prepared by spiking $200 \mu \mathrm{L}$ of blank human plasma with the appropriate amount of the analyte $(20 \mu \mathrm{L})$.

\section{Sample preparation}

$200 \mu \mathrm{L}$ of plasma sample and $20 \mu \mathrm{L}$ acetonitrile/water/formic acid mixture (20:80:0.2, v/v/v) were added to $1.5 \mathrm{~mL}$ polypropylene centrifuge tube and vortexed. Then, $500 \mu \mathrm{L}$ of IS working solution were added (containing $25 \mathrm{ng}$ of Bv, i.e. $125 \mathrm{ng} / \mathrm{mL}$ final IS plasma concentration) and the mixture was vortexed again. The samples were centrifuged for $10 \mathrm{~min}$ at $20000 \mathrm{rpm}$ on a benchtop centrifuge (Sigma 3K30C). The supernatant $(200 \mu \mathrm{L})$ was transferred to the glass autosampler vials containing $1000 \mu \mathrm{L}$ of $0.1 \%$ formic acid. The vials were capped, vortexed, and $4 \mu \mathrm{L}$ were injected into UPLC-MS/MS system.

\section{Method validation}

Full validation of the developed method was done in accordance with the requirements $[7,8]$. The method was validated for selectivity, LLOQ, calibration curve, within-run and between-run precision and accuracy, recovery, matrix effect and stability.

Six batches of blank plasma were used to determine the selectivity. Fn was added to plasma in quantity which corresponded to LLOQ (2 ng/ $\mathrm{mL}$ ); IS stock solution was added to achieve $125 \mathrm{ng} / \mathrm{mL}$ concentration in plasma. The given solutions as well as the blank plasma solutions which were prepared in triplicate as described above were analyzed, and the peaks areas from the corresponding chromatograms were compared.

The LLOQ was assessed using 5 solutions which were prepared on the blank plasma with the nominal concentration of $2 \mathrm{ng} / \mathrm{mL}$ Fn in plasma. We analyzed the given solutions and the blank plasma samples which were prepared according to the section "Sample preparation".

The calibration graph was evaluated by using 8 calibration 
standards with Fn concentrations in plasma of 2, 6, 20, 50, 100, 200, 300 , and $500 \mathrm{ng} / \mathrm{mL}$.

The accuracy and the precision of the method were evaluated using the model biosamples which were prepared in the group of five for each of four Fn concentrations in blank plasma equivalent: $2 \mathrm{ng} / \mathrm{mL}$ (LLOQ), $6 \mathrm{ng} / \mathrm{mL}$ (low QC), $100 \mathrm{ng} / \mathrm{mL}$ (medium QC), and $300 \mathrm{ng} /$ $\mathrm{mL}$ (high $\mathrm{QC}$ ). The experiment was conducted on three different days.

Within-run and between-run precisions were calculated using the formula \%R.S.D. $=($ S.D. $/ M) \times 100$, where $M$ is the mean of the experimentally determined concentrations and S.D. is the standard deviation of M. Accuracy was defined as the percent relative error $(\% \mathrm{RE})$ and was calculated using the formula $\% \mathrm{RE}=(\mathrm{E}-\mathrm{T}) \times 100 / \mathrm{T}$, where $\mathrm{E}$ is the experimentally determined concentration and $\mathrm{T}$ is the theoretical concentration.

The extraction recovery of $\mathrm{Fn}$ and Bv from plasma was determined at 3 concentrations: low, medium and high QC samples (3 replicates) by comparing the areas of extracted samples with the blank plasma extracts fortified with the drug post extraction [7].

The matrix effect was investigated using 6 batches of human plasma. For the analyte and the IS, the matrix factor (MF) was calculated for each batch of plasma by calculating the ratio of the peak area in the matrix presence (measured by analyzing the blank matrix spiked with the analyte at a concentration of $6 \mathrm{ng} / \mathrm{mL}$ after extraction (3 LLOQ) to the peak area in the mobile phase) [8].

Stability of the analyte in the studied matrix was evaluated using triplicates samples of the low and high QC samples which were analyzed immediately after preparation and after the applied storage conditions $[7,8]$. The short-term stability was examined following sample defrosting and 4-hour incubation at room temperature. The freeze-thaw stability was examined after three freeze-thaw cycles. The long-term stability was determined by analyzing five aliquots at nominal concentrations of 6 and $300 \mathrm{ng} / \mathrm{mL}$ stored at $-70^{\circ} \mathrm{C}$ for 150 days. The stability of the samples processed in autosampler was examined after 22 hours. The stock solutions stability was assessed after 1 month storage at a temperature of $-35^{\circ} \mathrm{C}$, working solution after the same storage period at a temperature of 2 to $7^{\circ} \mathrm{C}$.

\section{Application for bioequivalence study}

The bioequivalence study for coated tablets of fenspiride $80 \mathrm{mg}$ was conducted in accordance with the Declaration of Helsinki, GCP and GLP requirements. The protocol and associated informed consent forms were reviewed and approved by The Central Ethical Committee of Ministry of Healthcare of Ukraine, and the informed consent forms were signed by the volunteers prior to the study initiation. Twenty four healthy volunteers (aged 18-52) were enrolled in this study. The volunteers met the requirements of inclusion/exclusion criteria. They had no history of cardiovascular, hepatic, renal, gastrointestinal, hematologic and nervous or any acute or chronic diseases or drug allergy, and had stopped using any drugs 2 weeks prior to the study enrollment. The volunteers did not receive any concomitant medication within 2 weeks prior to screening as well as during the study. Physical examination and laboratory tests showed no abnormal findings. The volunteers were randomized in two groups of 12 . The cross over design was applied to this study when one subgroup was administered the study drug followed by administration of the reference drug, another subgroup was administered vice-versa. All subjects were administered a single dose of $80 \mathrm{mg}$ after overnight fasting. The subjects were required to refrain from smoking, alcohol, caffeine and were under direct medical supervision at the study site.

14 blood samples were drawn from each subject at each study time point. The blood sampling was conducted according to the following schedule: 0 h (pre-dose), 30 min, 1 h, 2 h, 4 h, 5 h, 6 h, 7 h, 8 h, 12 h, 24 $\mathrm{h}, 36 \mathrm{~h}, 48 \mathrm{~h}$, and $72 \mathrm{~h}$ post-dose. The samples were transferred in the lithium heparinized tubes ( $9 \mathrm{~mL}$ volume) and centrifuged within $1 \mathrm{~min}$ after collection. The centrifugation was conducted in the temperaturestabilized rotary chamber at $10^{\circ} \mathrm{C}$ for $5 \mathrm{~min}$ at $4000 \mathrm{~g}$. The plasma was divided into two aliquots (the first one was for the analysis, the second one was for back-up) but the volume was not less than $1.3 \mathrm{~mL}$ for each aliquot, which were transferred into the pre-labeled cryotubes. The plasma was kept at $-70^{\circ} \mathrm{C}$ at the study site and at the bioanalytical laboratory as well. The time period between blood collection and plasma transfer into $-70^{\circ} \mathrm{C}$ freezer did not exceed $12 \mathrm{~min}$.

23 volunteers completed the study, 1 subject withdrawn the consent prior to Period 1 because of adverse event (headache) treatment. All required results were included into pharmacokinetic parameters assessment. Totally, 655 frozen samples were submitted to the bioanalytical laboratory for assessment.

The data analysis of pharmacokinetic parameters was performed by using the Win-Nonlin professional software version 5.2 (Pharsight, Mountain View, CA, USA) using non-compartmental approach to the assessment model of "NCA Model 200". AUC ${ }_{0-72}$ values ( $\mathrm{t}$ being the time of the last plasma concentration measured) were calculated by the linear trapezoidal rule. The AUC from 0 to infinity $\left(\mathrm{AUC}_{0-\infty}\right)$ was calculated by the software. The first order rate constant, $\mathrm{K}_{\mathrm{el}}$, was estimated by the linear regression of time versus log of the concentration. The terminal half-life $\left(\mathrm{T}_{1 / 2}\right)$ was also calculated.

The bioequivalence was confirmed by the approach based on the statistically assessed $90 \%$ confidence intervals for the ratio of the average $\mathrm{C}_{\max }$ and $\mathrm{AUC}_{0-\mathrm{t}}$ parameters for the drug $\mathrm{A}$ and $\mathrm{B}$. The drugs were considered as bioequivalent if $90 \%$ confidence interval was within $0.80-1.25(80-125 \%)$ for the ratio of the average $C_{\max }$ and $\mathrm{AUC}_{0-t}$ parameters.

\section{Results and Discussion}

Liquid-liquid extraction without following evaporation and reconstitution of samples was used in the previously mentioned article [6]. Fenspiride and internal standard (trimetazidine) were extracted from plasma in 1-octanol and directly injected of large volume aliquot on the column. Total time required for chromatography of one sample in this method was $7 \mathrm{~min}$ (stop time of the method) due to a relatively long time period needed for washing off the immiscible diluent from the column. This period is much more than stop time of the method which we developed $(1.2 \mathrm{~min})$. The total time needed for the analysis is extremely important for the pharmacokinetic studies when large numbers of biosamples need to be analyzed.

\section{Samples preparation and chromatographic conditions}

Acetonitrile containing IS and $1 \%$ of formic acid has proved quite effective as an agent for plasma proteins precipitation at agent/plasma ratio 2.5:1 (v/v). The obtained supernatants were diluted with acidified water for harmonization with the starting chromatographic conditions.

The gradient profile was optimized to achieve good peak shapes and a short run time for the compounds, as well as to avoid the ion suppression. 
Citation: Pidpruzhnykov YV, Sabko VE, lurchenko VV, Zupanets IA (2013) UPLC-MS/MS Quantification of Fenspiride in Human Plasma. J Bioequiv Availab 5: 185-190. doi:10.4172/jbb.1000156

The typical chromatograms of a blank, a spiked plasma sample with Fn at LLOQ and IS, and a plasma sample from a healthy volunteer $12 \mathrm{~h}$ after oral administration and spiked IS are shown in Figure 2.

The data registration time was $1.2 \mathrm{~min}$. Such a short period of time allowed chromatography of each study sample to be conducted twice. The analysis of one sample took less than 3 minutes, taking into account the sampling in load ahead mode. The Fn concentration was calculated for the mean value of two parallel injections response. Significant time reduction on chromatography by the UPLC-MS/MS method is an indisputable advantage of the new approach as compared with the traditional HPLC-MS/MS. It is essential for conducting the bioequivalence study.

\section{Matrix effect, selectivity and recovery}

The matrix effect study showed that the ion suppression of Fn and $\mathrm{Bv}$ is practically absent under the selected conditions (Table 2). The
IS normalized MF $\left(\mathrm{MF}_{\mathrm{N}}\right)$ also was calculated by dividing the MF of the analyte by the MF of the IS [8]. The results obtained satisfy the requirements [8], since RSD of $\mathrm{MF}_{\mathrm{N}}$ calculated from 6 batches of matrix (3.0\%) is much less than $15 \%$.

During the selectivity estimation the mean "noise" peak area for each of six batches of plasma was less than $20 \%$ of the LLOQ for the analyte: $4.6,5.3,4.4,4.2,3.2$ and $2.3 \%$ respectively.

The extraction recovery of Fn was consistently high within a wide range of concentrations $(6-300 \mathrm{ng} / \mathrm{mL})$ : $99.3-101.9 \%$. The mean extraction recovery of $\mathrm{Bv}$ was equally high: $101.6 \%$.

\section{Calibration curve and lower limit of quantification}

The calibration curve was generated from 8 calibration standards prepared from blank plasma over the Fn concentration range of $2 \mathrm{ng} /$ $\mathrm{mL}$ to $500 \mathrm{ng} / \mathrm{mL}$. The results of the blank sample and zero sample
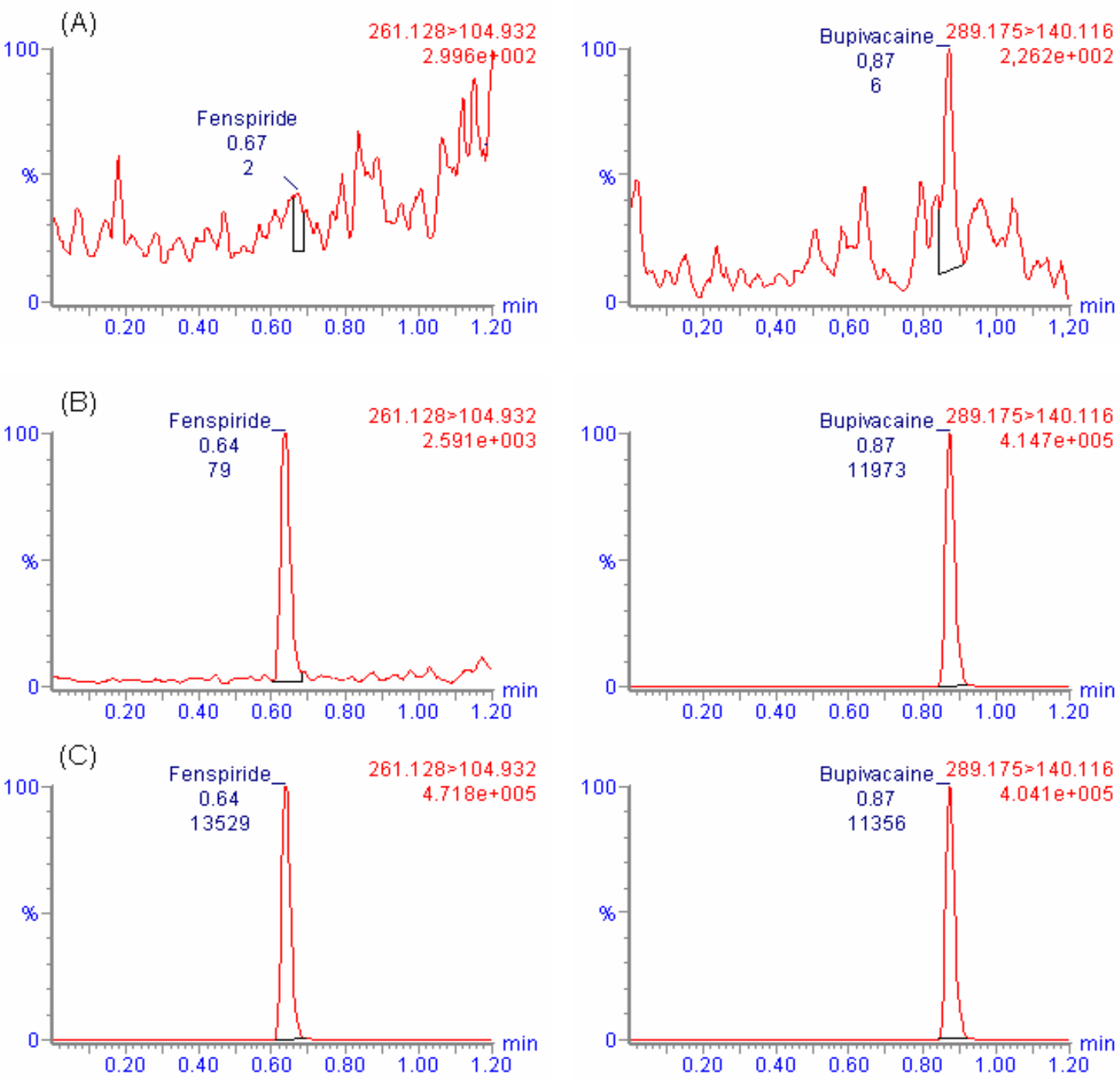

Figure 2: Typical MRM chromatograms of fenspiride (left panel) and bupivacaine (IS, right panel) in human plasma: (A) blank plasma sample; (B) blank plasma sample spiked with fenspiride ( $2 \mathrm{ng} / \mathrm{ml}, \mathrm{LLOQ})$ and IS (125 ng/ml); (C) plasma sample from a volunteer at $12 \mathrm{~h}$ after administration of Inspirone ${ }^{\circledR}$ tablets $(427 \mathrm{ng} / \mathrm{ml}$ of fenspiride found). 
Citation: Pidpruzhnykov YV, Sabko VE, lurchenko VV, Zupanets IA (2013) UPLC-MS/MS Quantification of Fenspiride in Human Plasma. J Bioequiv Availab 5: 185-190. doi:10.4172/jbb.1000156

were not taken into consideration when constructing the calibration function.

Partially, linear regression equation with the weighting factor $1 /$ concentration did not satisfy the acceptance criteria [7] because of unacceptable deviation of LLOQ standard. At the same time, quadratic model with the weighting factor $1 /$ concentration continuously described the calibration curve adequately.

The mean coefficients of the regression equation $\mathrm{Y}=\mathrm{aX} \mathrm{X}^{2}+\mathrm{bX}+\mathrm{c}$ had the following values $(n=7)$ :

$$
\mathrm{a}=-3.480 \cdot 10^{-7}, \mathrm{~b}=0.002638 ; \mathrm{c}=0.0001417 \text {. }
$$

The mean value of the coefficient of determination $\left(R^{2}\right)$ was 0.999 . The back calculated concentrations of the calibration standards complied with the acceptance criteria $[7,8]$.

The validated value of LLOQ was $2 \mathrm{ng} / \mathrm{mL}$ with the mean signal/ noise ratio 46.0. Five independent standards of the mentioned concentration and five blank biosamples were analyzed in order to obtain this value. The back calculated concentrations of the LLOQ standards were found with precision and accuracy within $\pm 15 \%$ (Table $3)$.

\section{Precision and accuracy}

Quintuple determination which was conducted in the five model biosamples for each of four chosen concentrations has shown that accuracy and precision were better (Table 3 ) than it was prescribed by the acceptance criteria [8].

\section{Stability}

The obtained stability results ( $\mathrm{RE}<12.9 \%$ for all kinds of stability and concentration ranges) indicate that the data comply with the acceptance criteria $[7,8]$. It was established that the model biosamples were stable for 150 days of storage at the temperature not higher than $-70^{\circ} \mathrm{C}$. Storage time of the real biosamples did not exceed 43 days.

\section{Bioanalytical study}

Mean plasma concentration - time profiles for 23 volunteers after oral administration of the test and the reference drug are presented in Figure 3.

Inspiron $^{\circledR}, \quad 80 \mathrm{mg}$ coated tablets, produced by JSC "Kievmedpreparat", Ukraine, has the pharmacokinetic profile similar to Eurespal, $80 \mathrm{mg}$ coated tablets, produced by "Les Laboratories Servier". The statistical analysis on all acquired data was performed

\begin{tabular}{|c|c|c|c|}
\hline $\begin{array}{c}\text { Batch of } \\
\text { blank plasma }\end{array}$ & $\mathbf{M F}_{\mathrm{Fn}}$ & $\mathbf{M F}_{\mathrm{Bv}}$ & $\mathbf{M F}_{\mathbf{N}}$ \\
\hline 1 & 1.01 & 1.03 & 0.976 \\
\hline 2 & 1.01 & 1.09 & 0.923 \\
\hline 3 & 1.03 & 1.07 & 0.964 \\
\hline 4 & 1.00 & 1.09 & 0.921 \\
\hline 5 & 1.06 & 1.07 & 0.985 \\
\hline 6 & 1.06 & 1.08 & 0.980 \\
\hline Mean & 1.03 & 1.07 & 0.958 \\
\hline RSD, \% & 2.6 & 2.1 & 3.0 \\
\hline
\end{tabular}

Table 2: Matrix factor of $\mathrm{Fn}\left(\mathrm{MF}_{\mathrm{Fn}}\right), \mathrm{Bv}\left(\mathrm{MF}_{\mathrm{Bv}}\right)$ and the IS normalized matrix factor of $\mathrm{Fn}\left(\mathrm{MF}_{\mathrm{N}}\right)$ in human plasma $(\mathrm{n}=6)$.

\begin{tabular}{|c|c|c|c|c|c|}
\hline & & $\begin{array}{l}\text { Spiked TMHP } \\
\text { concentration } \\
(\mathrm{ng} / \mathrm{ml})\end{array}$ & $\begin{array}{c}\text { Measured } \\
\text { TMHP } \\
\text { concentration } \\
(\mathrm{ng} / \mathrm{ml})\end{array}$ & $\begin{array}{c}\text { RSD } \\
(\%)\end{array}$ & RE (\%) \\
\hline \multirow{12}{*}{ Within-run } & \multirow{4}{*}{ Day $1, n=5$} & 1.990 & 1.894 & 3.8 & -4.8 \\
\hline & & 5.970 & 5.945 & 6.1 & -0.4 \\
\hline & & 99.50 & 91.46 & 3.7 & -8.1 \\
\hline & & 298.5 & 276.0 & 6.0 & -7.6 \\
\hline & \multirow{4}{*}{ Day $2, n=5$} & 1.990 & 2.238 & 4.4 & 12.4 \\
\hline & & 5.970 & 6.168 & 3.8 & 3.3 \\
\hline & & 99.50 & 91.36 & 1.9 & -8.2 \\
\hline & & 298.5 & 273.2 & 1.6 & -8.5 \\
\hline & \multirow{4}{*}{ Day $3, n=5$} & 1.990 & 2.040 & 9.5 & 2.5 \\
\hline & & 5.970 & 6.089 & 6.2 & 2.0 \\
\hline & & 99.50 & 95.78 & 3.5 & -3.7 \\
\hline & & 298.5 & 295.1 & 2.5 & -1.1 \\
\hline \multirow{4}{*}{$\begin{array}{l}\text { Between- } \\
\text { run }\end{array}$} & \multirow{4}{*}{3 days, $n=15$} & 1.990 & 2.057 & 9.3 & 3.4 \\
\hline & & 5.970 & 6.067 & 5.3 & 1.6 \\
\hline & & 99.50 & 92.87 & 3.7 & -6.7 \\
\hline & & 298.5 & 281.4 & 5.0 & -5.7 \\
\hline
\end{tabular}

Table 3: Within-run and between-run precision and accuracy.

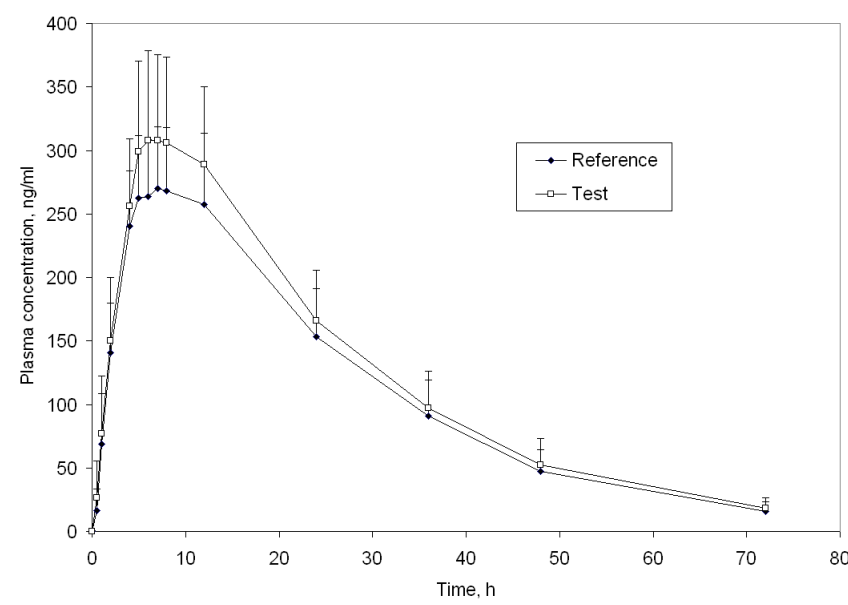

Figure 3: Mean plasma concentration-time profile of fenspiride following administration of $80 \mathrm{mg}$ tablets of Eurespal ${ }^{\circledR}$ (reference) and Inspirone ${ }^{\circledR}$ (test) to 23 healthy volunteers.

employing the ANOVA algorithm (Win-Nonlin professional software version 5.2). The main pharmacokinetic parameters and its standard deviations are listed in Table 4.

The data of the bioequivalence assessment of the given drugs are listed in Table 5. These findings suggest that the drugs are bioequivalent.

\section{Conclusion}

The new method of quantification of fenspiride in human plasma using UPLC-MS/MS was developed. The method proved to be rapid 
Citation: Pidpruzhnykov YV, Sabko VE, lurchenko VV, Zupanets IA (2013) UPLC-MS/MS Quantification of Fenspiride in Human Plasma. J Bioequiv Availab 5: 185-190. doi:10.4172/jbb.1000156

\begin{tabular}{|c|c|c|}
\hline Parameters & Test drug & Reference drug \\
\hline $\mathrm{C}_{\max }(\mathrm{ng} / \mathrm{ml})$ & $332.5 \pm 70.6$ & $284.5 \pm 49.4$ \\
\hline $\mathrm{T}_{\max }(\mathrm{h})$ & $7.61 \pm 2.57$ & $7.74 \pm 2.80$ \\
\hline $\mathrm{AUC}_{0-24}(\mathrm{~h} \cdot \mathrm{ng} / \mathrm{ml})$ & $9084 \pm 2020$ & $8123 \pm 1817$ \\
\hline $\mathrm{AUC}_{0-\infty}(\mathrm{h} \cdot \mathrm{ng} / \mathrm{ml})$ & $9487 \pm 2185$ & $8472 \pm 1954$ \\
\hline $\mathrm{AUC}_{0-24} / \mathrm{AUC} \mathrm{C}_{0-\infty}(\%)$ & $95.97 \pm 2.00$ & $96.09 \pm 2.03$ \\
\hline $\mathrm{K}_{\mathrm{el}}\left(\mathrm{h}^{-1}\right)$ & $0.0485 \pm 0.0068$ & $0.0494 \pm 0.0068$ \\
\hline $\mathrm{T}_{1 / 2}(\mathrm{~h})$ & $14.58 \pm 2.22$ & $14.31 \pm 2.21$ \\
\hline
\end{tabular}

Table 4: Mean pharmacokinetic parameters of $\mathrm{Fn}$ for 23 volunteers after administration of the study and reference coated tablets (mean \pm S.D., $n=23$ ).

\begin{tabular}{|c|c|c|c|c|c|c|}
\hline Drug & $\begin{array}{l}\mathrm{C}_{\max } \\
\mathrm{ng} / \mathrm{ml}\end{array}$ & $\begin{array}{l}{ }^{*} \mathrm{C}_{\max A} \\
\mathrm{C}_{\max }, \%\end{array}$ & $\Delta \mathrm{C}_{\max }, \%$ & $\begin{array}{l}\mathrm{AUC}_{0-\mathrm{t}} \\
\mathrm{h} \cdot \mathrm{ng} / \mathrm{ml}\end{array}$ & $\begin{array}{l}{ }^{*} \mathrm{AUC} \mathrm{C}_{0-\mathrm{t}} \mathrm{A} / \\
\mathrm{AUC}_{0-\mathrm{t}} \mathrm{B}, \%\end{array}$ & $\Delta \mathrm{AUC}_{0-\mathrm{t}}, \%$ \\
\hline Inspiron (A) & 332.5 & \multirow{2}{*}{115.9} & \multirow{2}{*}{$109.3-123.0$} & 9084 & \multirow{2}{*}{112.3} & \multirow{2}{*}{$106.4-118.5$} \\
\hline Eurespal (B) & 284.5 & & & 8123 & & \\
\hline
\end{tabular}

the ratio of geometric means is presented

Table 5: Results of bioequivalence study of tablets Inspiron ${ }^{\circledR}$ relative to tablets Eurespal ${ }^{\circledR}$.

and simple. The performed method validation has indicated the conformity of its properties with the established requirements. The method has been successfully applied to the bioequivalence study of generic and brand $80 \mathrm{mg}$ coated tablets of fenspiride.

\section{Acknowledgements}

We thank to JSC "Kievmedpreparat", Ukraine for funding the study.

\section{References}

1. Sauveur C, Baune A, Vergnes N, Jeanniot JP (1989) The determination of fenspiride in human plasma and urine by liquid chromatography with electrochemical or ultraviolet detection. J Pharm Biomed Anal 7: 1799-1804.

2. Montes B, Catalan M, Roces A, Jeanniot JP, Honorato JM (1993) Single dose pharmacokinetics of fenspiride hydrochloride: phase I clinical trial. Eur J Clin Pharmacol 45: 169-172.

3. Dumasia MC, Houghton E, Hyde W, Greulich D, Nelson T, et al. (2002) Detection of fenspiride and identification of in vivo metabolites in horse body fluids by capillary gas chromatography-mass spectrometry: administration, biotransformation and urinary excretion after a single oral dose. J Chromatogr B Analyt Technol Biomed Life Sci 767: 131-144.

4. Stanley SM, Foo HC (2006) Screening for basic drugs in equine urine using direct-injection differential-gradient LC-LC coupled to hybrid tandem MS/MS. J Chromatogr B Analyt Technol Biomed Life Sci 836: 1-14.

5. Van Thuyne W, Van Eenoo P, Delbeke FT (2007) Comprehensive screening method for the qualitative detection of narcotics and stimulants using single step derivatisation. J Chromatogr B Analyt Technol Biomed Life Sci 857: 259265.

6. Medvedovici A, Udrescu S, Albu F, Tache F, David V (2011) Large-volume injection of sample diluents not miscible with the mobile phase as an alternative approach in sample preparation for bioanalysis: an application for fenspiride bioequivalence. Bioanalysis 3: 1935-1947.

7. U.S. Department of Health and Human Services, Food and Drug Administration (2001) Guidance for industry: bioanalytical method validation. Rockville, MD.

8. European Medicines Agency (2011) Guideline on bioanalytical method validation. UK. 